\title{
Commercialization of innovations by hi-tech knowledge-intensive enterprises
}

\author{
Alexander Zheltenkov ${ }^{1, *}$ \\ ${ }^{1}$ Moscow Region State University, Radio str, 10A, 105005, Moscow, Russia
}

\begin{abstract}
Problems of commercialization of innovations by the hi-tech knowledge-intensive enterprises, compensation of expenses and receiving profit by the developer from consumers (future owners or users of the innovation) are considered in the article. Special attention is paid to the matters of the use of the modern organizational forms, consolidating the efforts of all the participants during commercialization and increasing their interest for the final result. The need of the analysis and assessment of the physical embodiment of a novelty at each stage of its transformation into an innovation, as it allows choosing a concrete way of commercialization of innovations more consciously, is proved. The authors confirm the need to assess the results of commercialization of innovations, to consider the complex of the commercial indicators, generating information on social, budgetary, economic effect, taking into account the influence on these indicators of factors of external and internal environment of the enterprise.
\end{abstract}

\section{Introduction}

Innovative transformations in the industry, in the research and educational spheres, in the field of public administration and business act as the distinctive features of the development of the modern world economy. The founder of the theory of innovations Josef Schumpeter for the first time mentioned innovations in 1911 as the result of creation of the new benefits or new quality, which are already existing, introductions of a new method (way) of production, development of new markets, the use of new types of raw materials, modification of the organization of production, distribution, exchange and consumption [1]. Taking into account this approach, further innovations were considered in many aspects, and the very concept "innovation" was treated in different ways in the scientific literature. The results of long-term discussions on the essence and definition of the concept "innovations" were brought by such significant international standard as "Oslo Management" [2], which defined that the innovation is the result of scientific activity, realized in a new product or process and which is used in practice. The same approach was legislatively fixed in Russia in 2011, when it was stated, that innovations is "a new or much improved product (goods, service) or process, put into practice; a new method of sales or a new organizational method in business practice, in organization of working place or in external relations". I.e. it is possible to consider innovations to be the realized novelties,

\footnotetext{
* Corresponding author: angela-1309.m@yandex.ru
} 
which have scientific-and-technical originality, production applicability and commercial feasibility.

It is well known [3] that the hi-tech knowledge-intensive enterprises, which develop and commercialize the original innovative goods, products and technologies, render intellectual services in the field of the high technologies (high technology, high tech, hi-tech) based on results of basic and applied researches, play a significant role in creation of innovations. Significant success was achieved by such enterprises in the creation of information-andcommunication technologies, perspective control systems, nanotechnologies, robotics, biomedical and genomic engineering, and functional materials of the improved properties.

\section{Methods}

Subject of researches was studying of features of commercialization of innovations by the hi-tech knowledge-intensive enterprises.

Studying of the main organizational forms consolidating efforts all participating in process of commercialization and increasing their interest in the end result became a research objective.

For the solution of a goal was need of the analysis and assessment of the physical embodiment of an innovation at each stage of its transformation into an innovation, with confirmation of expediency of accounting of a complex of commercial indicators is proved at assessment of results of commercialization of innovations and definitions of influence on these indicators of factors of external and internal environment of the enterprise.

The economic method of comparative analysis and generalization, synthesis and induction were applied as the main method of research, when forming conclusions. Works of many scientists, who studied the features of innovative activity, became the theoretical basis and empirical base of the research.

\section{Results}

In general the process of creation and realization of a novelty for such enterprises consists of several consistently realized stages, presented in Figure 1.

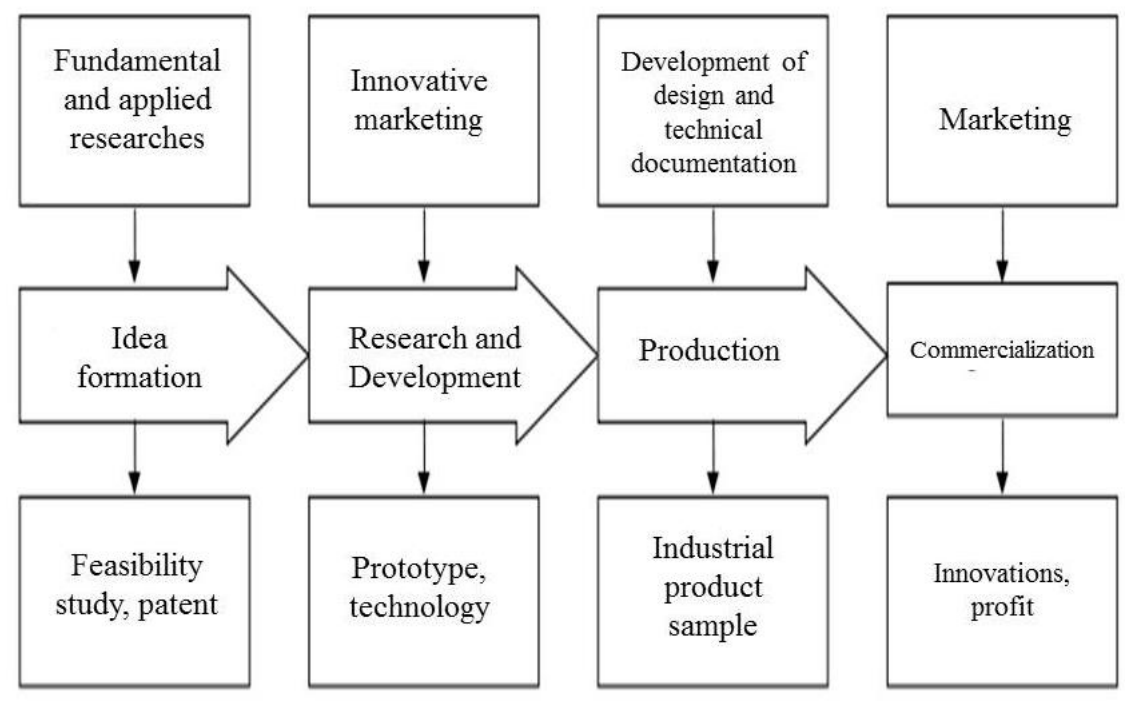

Fig. 1. Sequence of stages of creation and realization of innovations. 
It is obvious that creation and realization of novelty are expensive, long and (the main thing) they are a very risky project. Life cycle of such project, as a rule, begins with the formation of the idea of an innovation on the basis of the results of basic and applied researches and its feasibility study (FS). Further the stage of research and development, including justification of the possibility of production, the marketing analysis of estimated demand, creation of a prototype, follows. Then during the production phase of innovative products its design and technological documentation is developed, the industrial product sample is created, its testing, certification and examination is held, and serial production itself begins. Production of innovations comes to the end with their commercialization, i.e. sale to the consumer and distribution of profit among the participants. Certainly, depending on specifics of creation and realization of an innovation, the process can include also other stages. One thing remains invariable, that is commercialization of an innovation with marketing and generation of profit remains a closing stage always. Therefore a difficult way from the emergence of the idea before industrial production it is also sold the products demanded by the market, it is possible to call set of ordered actions for commercialization of innovations.

Commercialization of innovations is considered to be the key stage of innovative activity, as it leads to the transformation of a novelty into an innovation and in case of success it provides the compensation of expenses and receiving profit by the developer, gained thanks to consumers (future owners or users of the innovation). At the same time, during commercialization of innovations, there are some traditional problems, among which the following ones can be distinguished:

- limitation of financial resources of the enterprise, which is often connected with considerable capital intensity and duration of the creation of innovations cycle;

- limitation of information on the innovations, offered by the developer;

- riskiness of the activity because of the probability of non-receipt of the planned results;

- discrepancy of innovative potential to the solvable tasks;

- mistrust of consumers to the presented results of the activity.

Nevertheless the key problem is the limitation of financial resources. Therefore the creation and commercialization of innovations is very seldom carried out by the hi-tech knowledge-intensive enterprises independently, because of limited own opportunities, though such option provides the fastest compensation of the funds, as the final off-taker of the products always closes the most significant cash flows on himself or herself. The arising financial, organizational and marketing problems usually demand attracting investors, other subjects, as a rule, having competences and experience in the conditions of the market. In most cases such measures sharply increase the probability of the planned results achievement. The scheme of such interaction and its participants is submitted in Figure 2.

First of all, small and medium enterprises, the innovative enterprises at the universities, startups (enterprises beginners) can act as the hi-tech knowledge-intensive enterprises, as developers of innovations, because all of them usually differ in dynamism, maneuverability, flexibility and good adaptability to market conditions. However it is impossible to underestimate the opportunities in creation of innovations of the research organizations, associations, corporations and holdings having significant innovative potential. Their activity in cooperation with the small and medium innovative enterprises due to acceleration of processes of creation and commercialization of innovative products, technologies and services on the basis of sharing of competences is especially effective. Moreover, there are also scientists-innovators, who are independently advancing the perspective ideas. The natural and legal entities, promoting their innovative activity and commercialization of their innovative developments, can be necessary for each of these groups of developers. 


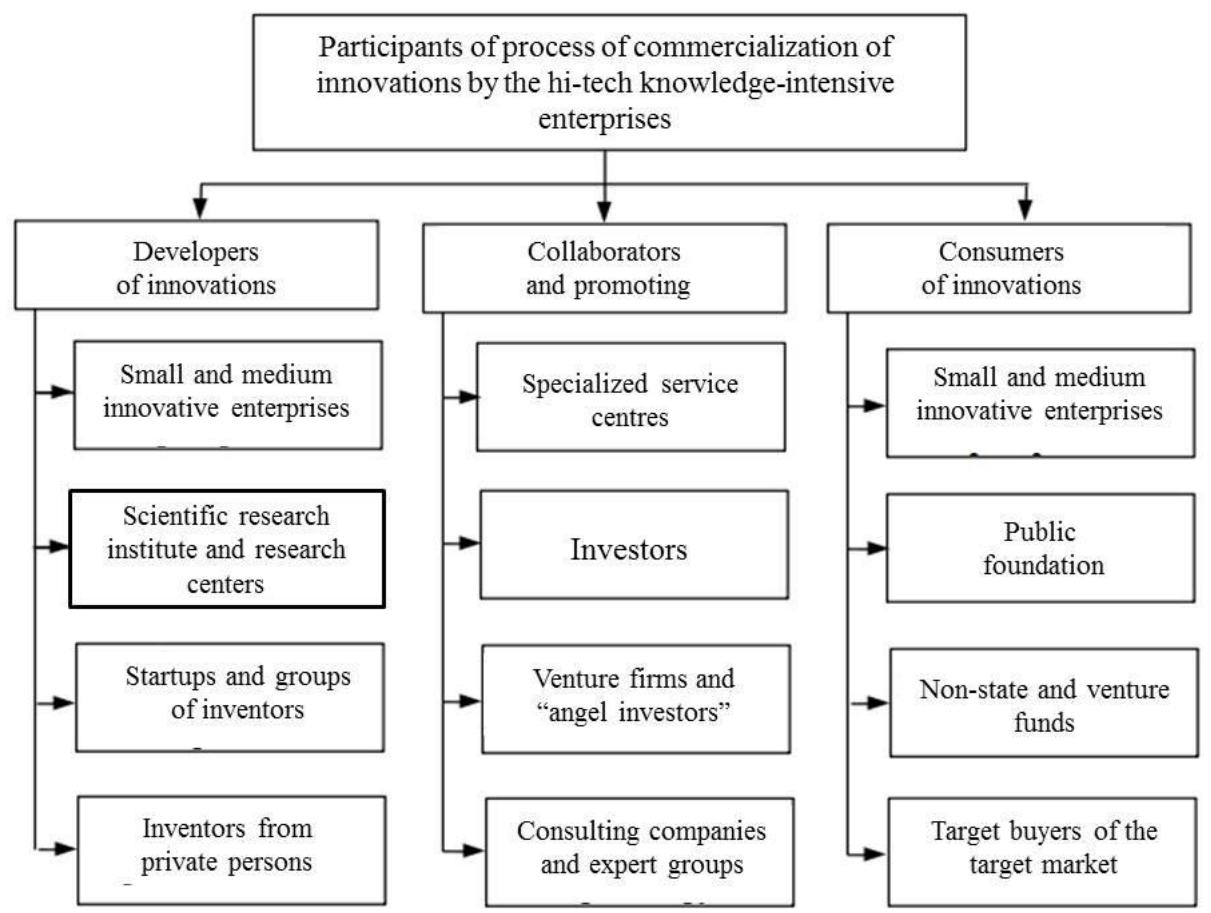

Fig. 2. Participants of the process of creation and commercialization of innovations.

Specialized service centers, consulting companies and expert groups, rendering services in the field of development of business and marketing of innovative projects, can promote commercialization. Some of the best places for the implementation of the breakthrough ideas are business incubators and science-and-technology parks, which are the organizations, providing the solution of problems of support of small enterprises and inventors from natural persons during creation on the basis of their ideas of innovative products, technologies, goods, services. The investors, financing research and development during the first stages of process (funds of basic research, scientific-and-technological centres), which can become further consumers of innovations can become the second group of promoting. It is also possible to name such investors as venture funds and angel investors. Their activity most often has concrete investment focus and, quite often, means partial or full transfer of rights to development results. The need of the use of consulting companies and expert groups as promoting innovations is connected, first of all, with the deficiency of the experts, who would have sufficient qualification in innovative projects management. Many enterprises need such services and also professional advance, expert estimates and so on during the initial stage. Consumers of innovations of the hi-tech knowledge-intensive enterprises at the present stage of development are large and medium enterprises, various funds. It should be noted that many non-state funds, including venture, can be not only consumers of innovations, but also to promote their creation. Difficult relationship between the developers of innovations promoting success of their activity and consumers leads to the emergence of the "niche market", providing the set of economic interactions between its participants, including target buyers. Such interaction in the market environment, undoubtedly, combines efforts of all the participants of the process of commercialization and increases their interest in the achievement of the final result. 
Possible ways of interaction of the participants of the process of commercialization of innovations are presented in Figure 3.

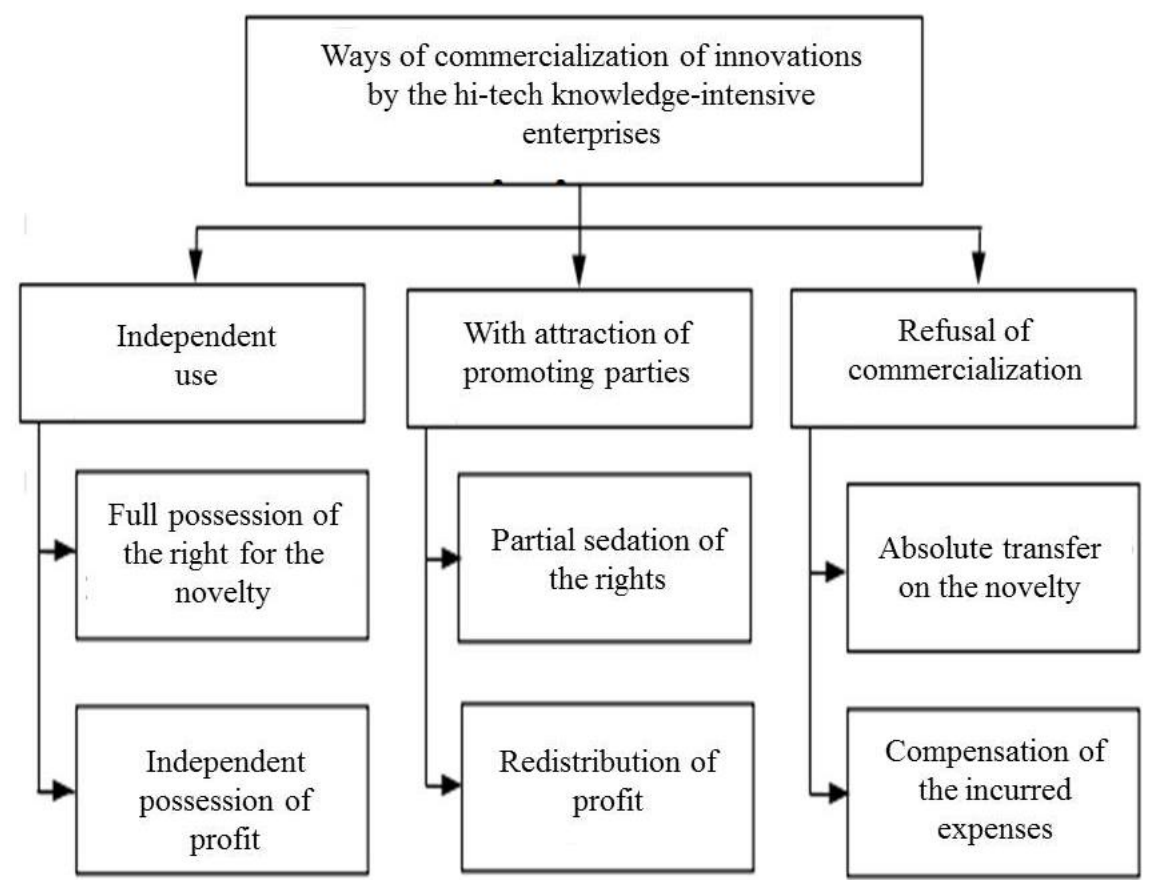

Fig. 3. Ways of commercialization of innovations.

It is obvious that any of the presented opportunities has its positive and negative sides, connected with expenses, various risks, factors of the external environment, behavior of competitors, etc. Therefore the concrete operations procedure, chosen by the enterprise decides both by goals, and the available opportunities, including rationality of actions of the enterprises, the nature of their interaction on collaborators, investors, suppliers. Also some external factors, including the characteristic regional heterogeneity, caused by the differences in the available resources, economical geographic location, conditions of the scientific and technological sphere and so forth, influences the choice of the business strategy of the enterprises in the competitive environment. Therefore it is necessary to choose the way of commercialization and the completion stage of the project, which are the most suitable for the current situation, considering some factors: type and the field of the use of the innovation, size and possibilities of the enterprise, the purpose and activity, the position in the competitive environment, some other factors [4].

However it is necessary to consider, that independent or partial possession of a novelty increases the innovative capacity of the enterprise whereas the refusal of commercialization with its transformation into an innovation, at best leaves it invariable. The partial cedation of the rights for innovations can be carried out by sale of licenses, transfer of a know-how, franchizing or commercial concession, transfer of the right for the use to promoting persons, including to investors. Full transfer provides alienation of the right for an innovation for the subsequent production of the final product by third party for the fixed or periodic remuneration. As a rule, full transfer of the right for an innovation happens in case the enterprise does not see technical capability, or economic and market feasibility to carry out commercialization not only with the attraction promoting its success, but also independently. It is also necessary to note that partial or absolute transfer on an innovation 
already new enterprise can be carried out during any stage of innovative activity, and thus being the owner, one will bring an innovation to consumers $[5,6,7]$.

As the physical embodiment of a novelty during various stages of innovative activity differs, we generalized the commodity form of innovations during the stages of their creation and realization in the Table 1.

Table 1. Physical embodiment of novelties during the stages of creation and realization.

\begin{tabular}{|l|l|}
\hline $\begin{array}{l}\text { Stages of creation of } \\
\text { innovations }\end{array}$ & \multicolumn{1}{|c|}{ Physical embodiment of a novelty } \\
\hline Idea formation & Idea, patent \\
\hline $\begin{array}{l}\text { Research and } \\
\text { development }\end{array}$ & Technology, prototype of products, know-how \\
\hline Production & Serial technology and serial product sample, know-how \\
\hline Commercialization & $\begin{array}{l}\text { Innovative technologies, goods, services. Shared profit on product } \\
\text { sales }\end{array}$ \\
\hline
\end{tabular}

Certainly, the physical embodiment of a novelty at each stage listed in the table, demands the analysis and assessment, as they can help is to choose a concrete way of commercialization of innovations more knowingly. High uncertainty of results of commercialization of an innovation is also connected with that. In our opin6.7ion, the most logical sequence of necessary actions according to efficiency of innovations is presented in the work [8] where it is offered to be carried out step by step, with determination of potential social, budgetary and economic effect. Such approach allows not only to make calculation of commercial indicators from the use of an innovation (which is important for determination of its investment attractiveness), but also to make calculation of key economic indicators of efficiency of the enterprise activity. It is necessary to agree with the arguments of the authors of some works [9, 10,11] that calculation of commercial effectiveness of an innovation is the most significant from the profitable point of view, as not only strategic planning of innovative development of the enterprises, but also the prospects of commercialization of their innovations depends on its accuracy. One more argument of the need of assessment of an innovation during each stage of an innovative product is the possibility of its manifestation at all natural and legal entities promoting innovative activity in the form of increase in volume of works and services, and, therefore, increases in taxable base.

Taking into account the conducted research, it is obvious that further improvement of innovative activity of the hi-tech knowledge-intensive enterprises has to be based on the complex actions for commercialization of innovations within the uniform organizationaland-economic mechanism [12].

\section{Conclusions}

It is revealed, that commercialization of innovations should be rightfully considered to be the key stage of innovative activity, as in case of success it provides compensation of expenses and receiving profit by the developer thanks to consumers (future owners or users of the innovation). Such interaction has to be made with the use of the organizational forms, which consolidate the efforts of all the participants of the process of commercialization and increase their interest in the final result. We have demonstrated how such forms of commercialization of innovations are defined and implemented and taking into account some factors. The need of the analysis and assessment of the physical embodiment of the novelty during each stage of its transformation into an innovation is proved, as it allows to choose a concrete way of commercialization of innovations more knowingly. The need to 
consider the complex of the commercial indicators, generating information on social, budgetary, economic effect taking into account influence on these indicators of factors of external and internal environment of the enterprise during the assessment of the results of commercialization of innovations is confirmed.

\section{References}

1. J.A. Schumpeter, The theory of economic development: An inquiry into profits, capital, credit, interest, and the business cycle (Transaction Publishers, New Brunswick, 1983)

2. O. Manual, Guidelines for collecting and interpreting innovation data. The measurement of scientific and technological activities (OECD Publishing, Paris, 2005)

3. S.S. Poloskov, A.V. Zheltenkov, Bulletin of Moscow Region State University, Series: Economics 2, 155-163 (2018)

4. A. Datta, R. Reed, L. Jessup, American Journal of Business 28(2), 147-191 (2013)

5. A. Mottaeva, A. Zheltenkov, MATEC Web of Conference 170, 01022 (2018)

6. D. Radushinsky, A. Mottaeva, L. Andreeva, G. Dyakova, IOP Conf. Series: Earth and Environmental Science 90, 012137 (2017) doi :10.1088/1755-1315/90/1/012218

7. E. Vasilyeva, MATEC Web of Conference 193, 01025 (2018)

8. O.M. Fokina, A.V. Krasnikova, Organizer of Production 25(3), 66-75 (2017)

9. V. Chiesa, F. Frattini, Journal of Product Innovation Management 28(4), 437-454 (2011)

10. A.V. Sukhorukov, Russian Journal of Entrepreneurship 15(8), 64-70 (2014)

11. A. Mottaeva, MATEC Web of Conferences 170, 01053 (2018) doi: 10.1051/matecconf/201817001053

12. G. Dyakova, S. Izmaylova, A. Mottaeva, E. Karanina, IOP Conf. Series: Earth and Environmental Science 90, 012218 (2017) doi: 10.1088/1755-1315/90/1/012218 